\title{
QUANTITATIVE ANALYSIS OF CEREBROSPINAL FLUID BRAIN DERIVED NEUROTROPHIC FACTOR IN THE PATIENTS WITH MULTIPLE SCLEROSIS
}

\author{
Farhad Mashayekhi', Zivar Salehi', Hamid Reza Jamalzadeh'
}

Islamic Azad University, Tonekabon branch, Tonekabon, Iran: Department of Biology1; Faculty of Medicine ${ }^{2}$

\begin{abstract}
Summary: Multiple sclerosis (MS) is the most common cause of nontraumatic neurological disability in Europe and North America. Growth factor expression could participate in the repair process of the demyelinating disease. Among growth factors, brain derived neurotrophic factors (BDNF) has been demonstrated to play an important role in neuronal and axonal survival. In the central nervous system (CNS), neurons are the main source of BDNF. Another potential source are activated astrocytes, which are present in inflamed areas in the CNS as shown in MS. In this study, total protein concentration (TPC) and BDNF levels in the cerebrospinal fluid (CSF) samples from the patients with MS ( $\mathrm{n}=48)$ and control subjects $(n=53)$ were measured using a Bio-Rad protein assay and enzyme linked immunosorbent assay (ELISA). No significant change in the CSF TPC of patients with MS was seen as compared to normal CSF. The presence of BDNF in the CSF samples was shown by Western blot. Using ELISA, it was shown that the level of BDNF in the MS CSF is higher than in normal CSF. It is concluded that BDNF is a constant component of human CSF. Moreover, it could be implicated in the pathophysiology of MS.
\end{abstract}

Key words: Brain derived neurotrophic factor; Cerebrospinal fluid; Multiple sclerosis

\section{Introduction}

Multiple sclerosis (MS) is a common, heterogenous disorder of the central nervous system (CNS) with a complex trait composed of both genetic and environmental factors. It is an inflammatory, immune-mediated chronic disorder of the CNS characterized by a combination of demyelination, axonal damage followed by degeneration and reactive gliosis $(4,7)$. In general, MS begins at third or fourth decade of life and affects more women than men (19). Susceptibility to MS varies in different ethnic groups (26). Although the complex pathogenesis of MS is not understood, an immune reaction against myelin sheath is suggested to be the primer event $(10,1)$.

MS lesions are characterized by inflammatory demyelination and reactive gliosis and although remyelination occurs in some lesions, it is limited and incomplete (22). Growth factor expression could participate in the repair process of MS by modulating the activity of microglial/ macrophages, and by inducing the expression of other factors that can affect myelin degeneration, and also by directly stimulating the localized proliferation and/or regeneration of oligodendrocytes within lesions area (6). Among cytokines and growth factors, brain derived neurotrophic factor (BDNF) has been shown to play a key role in neuronal and axonal survival. In the CNS, neurons are the main source of BDNF (11). Another potential source are activated astrocytes, which are present in inflamed areas in the CNS as shown in MS and also Alzheimer's disease $(25,3)$. The expression of neurotrophins and their receptive receptors has also been detected in lymphoid organs such as thymus and spleen (27). Moreover, activated T cells, B cells and monocytes express bioactive BDNF in vitro and in MS (13). BDNF and its receptor, TRK, have been found in active MS lesions (16).

BDNF is a homodimeric protein released in the synapses and presents a widespread distribution in the CNS. Interaction of BDNF with its receptor, TRK, is essential in a series of cognitive functions, such as learning and memory and seems to play a role in the synaptic plasticity (21, 12). BDNF is widely expressed in the mammalian brain and is present in the cerebrospinal fluid (CSF) (15). Changes in the BDNF protein expression in the brain of individual with neurodegenerative diseases including Parkinson's disease (PD) have been reported (20). It has also been shown that the concentration of CSF BDNF was increased in the patients with PD as compared to normal CSF (23).

As early detection of MS is beneficial for the treatment of patients, the search for diagnostic markers in CSF has become a rapidly growing field. CSF can be tested for the diagnosis of a variety of neurological diseases (2). There seems to be a close relation between the concentrations of these proteins in the CSF and the severity of brain damage. As CSF is in contact with the extracellular space of 
the brain, and changes in the cytokines and growth factor levels in the CSF have been seen in many neurological diseases (18), biochemical brain modifications could be reflected in CSF and measurements of growth factors might identify biomarkers of MS. In this study the CSF total protein concentration and BDNF levels of patients with MS was studied by Bio-Rad protein assay, western bloting and enzyme linked immunosorbent assay (ELISA).

\section{Materials and methods}

\section{Antibodies and reagents}

Avidin-Biotin peroxidase complex and Diaminobenzidine were purchased from Vector Laboratories, Peterbrough, UK. The anti-BDNF antibody (Code: ab6201) and BDNF human ELISA (Code: ab99978) were purchased from Abcam, Cambridge, UK.

\section{CSF samples}

Forty eight patients with relapsing-remitting multiple sclerosis (RRMS) (12 males and 36 females, age \pm SEM (standard error of the mean): $35.44 \pm 4.33$ ) and fifty three normal subjects (20 males and 33 females, mean age \pm SEM: $37.55 \pm 5.77)$ were recruited in this study. All patients underwent a standard battery of examinations, including medical history, physical and neurological examinations, screening laboratory test, brain magnetic resonance imaging (MRI) and lumbar puncture. All patients with RRMS were in an acute phase of the disease.

All of normal subjects underwent lumbar puncture for subjective symptoms with no evidence of objective pathological conditions were included in this study. An informed consent to participate in this study was given by all individuals. Characteristics of patients and control groups are summarized in Table 1.

Tab. 1: Characteristics of MS patients and normal control groups

\begin{tabular}{|l|c|c|}
\hline & RRMS* & $\begin{array}{c}\text { Normal } \\
\text { control }\end{array}$ \\
\hline Number of subjects & 48 & 53 \\
\hline Gender (M : F) & $12: 36$ & $20: 35$ \\
\hline $\begin{array}{l}\text { Age at sampling, years } \\
\text { (mean } \pm \text { SEM) }\end{array}$ & $35.44 \pm 4.33$ & $37.55 \pm 5.77$ \\
\hline
\end{tabular}

RRMS; relapsing-remitting multiple sclerosis

CSF from normal subjects and MS patients were collected by lumbar puncture performed routinely on the basis of the clinical suspicion of neurological disease. None of the patients suffered from known diabetes mellitus, earlier diagnosed tumors of the nervous system or infection. Samples were taken from both male and female patients. For the lumbar puncture the skin were cleaned with $70 \%$ alcohol. $0.5 \mathrm{ml}$ of CSF were collected and used for this study. The samples that we used for analysis had no visible sign of contaminating neuroepithelium cells or red blood cells detectable under the microscope. The CSF samples were collected and analyzed for oligoclonal bands (OCBs) by agarose gel electrophoresis on the same day as specimen collection. The finding of OCBs in CSF and not in the serum supports the diagnosis of MS. Only the OCBs positive CSF samples were included in this study for BDNF analysis. The samples subsequently were stored at $-70^{\circ} \mathrm{C}$ for further analysis.

All data presented are expressed as mean \pm standard error of the mean (SEM). Statistical analysis was performed using Student's $t$-test and only values with $P \leq 0.05$ were considered as significant.

\section{Analysis of CSF protein}

Total protein concentration and Western blot: The total concentration of proteins in CSF samples was determined by the Bio-Rad protein assay based on the Bradford dye procedure. For Western blot analysis, CSF samples were mixed with a sample buffer containing 3.2\% SDS, $15 \%$ glycerol, 2.8 M b-mercaptoeyhanol and $0.0015 \%$ bromophenol blue. Samples were applied to a 10\% SDS-PAGE gel (BioRad, Milan, Italy) and the proteins obtained were transferred to nitrocellulose sheets, pore size $0.45 \mathrm{~lm}$ (Bio-Rad). After incubation for 2 hours at room temperature in the blocking solution (PBS containing 5\% skimmed milk), the nitrocellulose sheets were exposed overnight, at $4{ }^{\circ} \mathrm{C}$, to anti-BDNF polyclonal antibody (Abcam) and identified with a peroxidase-labeled mouse IgM PK 4010 Vectastain Avidin Biotin complex kit (Vectorlab, Peterborough, UK). The peroxidase activity was revealed with diaminobenzidine $(0.5 \mathrm{mg} / \mathrm{ml}$ in PBS with $0.02 \%$ hydrogen peroxide). $\beta$-Tubulin expression was determined as a protein loading control. After Western blotting, the data were quantified by scanning densitometry.

ELISA: BDNF level in CSF was measured using the sensitive two sited ELISA and antiserum against human BDNF. Microtiter plates (Dynatech, Chantilly, VA) were first coated with 80 ng primary anti-BDNF antibody per well in 0.1 M Tris buffer. After overnight incubation, the plates were blocked with EIA buffer (50 mM Tris, pH 7.5, 0.3 M NaCl, $0.1 \%$ Triton X-100, $1 \%$ BSA and $1 \%$ Gelatine). The samples and standards were placed in triplicate wells and incubated overnight at room temperature. After washing a biotinylated secondary antibody $(8 \mathrm{ng} / \mathrm{ml})$ was added to each well and the incubation was carried out overnight at room temperature. b-Galactosidase coupled to avidin was then added and after two hours was followed by washing. Finally $200 \mu \mathrm{M} 4-$ methylumbelliferyl-b-galactoside (Sigma, Poole, UK) in $50 \mathrm{mM}$ sodium phosphate and $10 \mathrm{mM} \mathrm{MgCl} 2$ buffer were added and the amount of fluorescence was measured after 40 minutes incubation at $37^{\circ} \mathrm{C}$ using a fluorimeter (Dynatech). 


\section{Results}

The total concentration of proteins in CSF from patients with MS and control subjects was determined by the Bio-Rad protein assay. The total protein contents of CSF samples from patients with MS and the control subjects were $0.37 \pm 0.06$ and $0.36 \pm 0.04 \mathrm{~g} / \mathrm{l}$, respectively. No significant difference has been seen in total protein concentration between two groups $(\mathrm{P}=0.55)$ (Fig. 1).

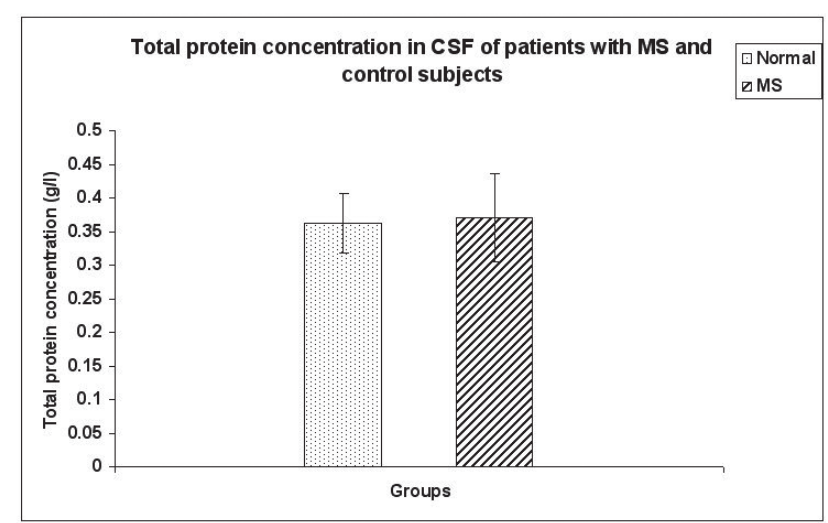

Fig. 1: Total protein concentration in the CSF of normal subjects and patients with MS $(\mathrm{g} / \mathrm{L})$. No significant difference has been seen in total protein concentration between the groups.
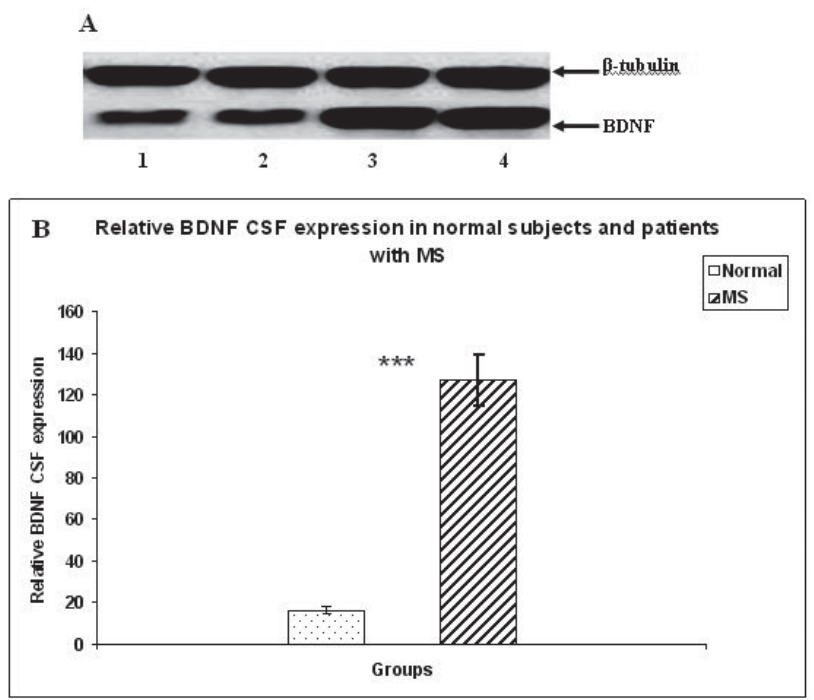

Fig. 2: (A) Expression of BDNF in the CSF samples from patients with MS (lanes 3 and 4) and normal subjects (lanes 1 and 2). The arrows indicate the position of BDNF and $\beta$-tubulin. $\beta$-tubulin $(50-\mathrm{kDa})$ expression was determined as a protein loading control. (B) Signal intensities from the anti-BDNF immunoblotting experiments A were determined by densitometric analysis. Significance values are shown as stars: 3 stars $\mathrm{P}<0.0001$.
A Western blot analysis using anti-BDNF antibody as a probe confirmed the presence of BDNF (Fig. 2A). In order to obtain semi-quantitative estimates of the relative amounts of $27 \mathrm{kDa}$ protein, an image analyzer was used to determine the intensities of the band in the respective lanes. Quantification of the gels from repeated experiments showed that the amount of BDNF was clearly increased in the CSF from patients with MS when compared with the normal CSF ( $\mathrm{P}<0.0001)$ (Fig. 2B).

Using ELISA, it was shown that the level of BDNF in the CSF samples with MS was higher than in normal CSF. The mean BDNF concentration in CSF of MS patients was amounted to $70.54 \pm 12.53 \mathrm{pg} / \mathrm{ml}$, which was significantly higher than that of normal, i.e. $8.64 \pm 1.52 \mathrm{pg} / \mathrm{ml}$ (Fig. 3) $(\mathrm{P}<0.0001)$. This study has shown that BDNF is present in human cerebrospinal fluid. The expression of CSF BDNF in patients with MS is more than that in normal CSF.

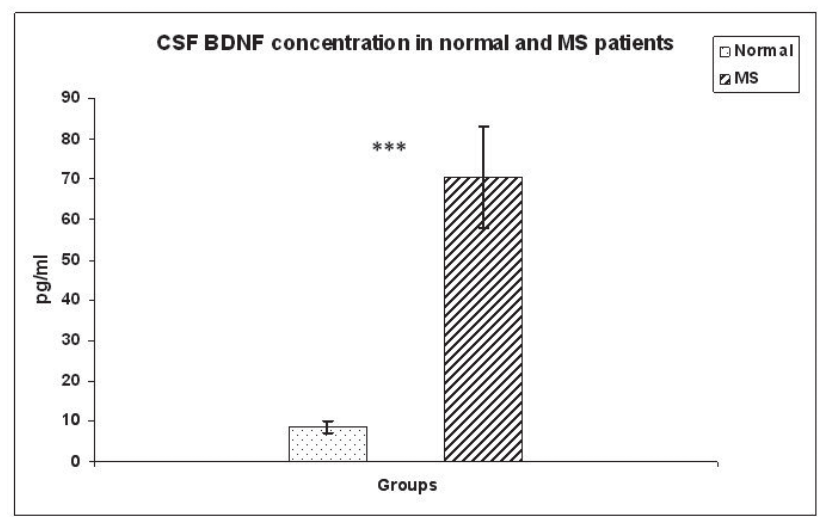

Fig. 3: BDNF levels in the CSF samples from controls and patients with MS (pg/ml). Significant increase in CSF BDNF level has been seen in MS samples when compared with normal $(\mathrm{P}<0.0001)$. Significance values are shown as stars: 3 stars $\mathrm{P}<0.0001$. Abbreviation: $\mathrm{MS}=$ multiple sclerosis.

\section{Discussion}

This study demonstrates that there are increased concentrations of BDNF in the CSF of patients with MS compared with normal subjects. We investigated BDNF as it is an important neurotrophic factor that has the capability to promote neuronal survival and induction of oligodendrocyte proliferation and myelination (17). BDNF belongs to the nerve growth factor (NGF) family of neurotrophins. In the CNS a widespread distribution of BDNF mRNA and protein has been demonstrated with high levels in hippocampal region (5). There are various physiological effects assigned to BDNF such as an important role in the development of fetal and postnatal brain, neurogenesis and synaptic plasticity as well as regeneration of neurons and axons after injury. It is also thought to influence oligodendrocyte proliferation and remyelination (17), which makes it an interesting factor in the context of MS. 
BDNF is not only important for the normal development of the peripheral and central nervous systems, but also active in the adult CNS, and might be involved in the pathology and pathophysiology of CNS diseases, notably MS (8). In the brain, BDNF is released by neurons and plays key roles in synaptic plasticity. BDNF and its receptor, TRK, have been found in active MS lesions (25).

Several lines of evidence show that inflammation may have, besides the detrimental effects on the nervous system, a neuroprotective role based on that immune cells are the major source of BDNF in neuroinflamatory diseases (9). Active demyelinating MS plaques harbor numerous BDNF positive inflammatory cells and astrocytes (25). As BDNF is an important cytokines that stimulates oligodendrocyte proliferation and survival, increased CSF BDNF concentration in the patients with MS seen in our study may be a compensatory mechanism in response to loss of oligodendroxyte in MS. In the normal brain, neurons have a major role in the synthesis of BDNF, while in injured brain, glial cells produce BDNF (14). The elevation of BDNF concentration in the CSF of patients with MS in this study may be the result of increased generation of glial cells resulting from brain damage. Since many neurons are destroyed and replaced by reactive gliosis, the elevation of BDNF in CSF may be amplified. If there is extensive damage of neurons, reactive glial cells rather than neurons may be the major source of BDNF in CSF. Production of BDNF by glial cells in patients with MS may represent an active response to neurodegenerative changes. Activated microglia express cytokines and neurotrophic factors that may be neuroprotective (24).

\section{Conclusions}

In summary, the CSF BDNF concentration is increased in patients with MS, which suggests that it is involved in neurodegeneration. Thus, we conclude that BDNF is not only a constant component of human CSF, but also might be involved in the pathophysiology of MS.

\section{Acknowledgements}

We would like to thank Dr Nouri, for the cerebrospinal fluid samples. The authors would also like to thank Dr E. Mirzajani, Guilan University of Medical Sciences, for ELISA.

\section{References}

1. Balcer LJ, Baier ML, Kunkle AM, et al. Self-reported visual dysfunction in multiple sclerosis: results from the 25-Item National Eye Institute Visual Function Questionnaire (VFQ-25). Mult Scler 2000; 6: 382-5.

2. Beems T, Simons KS, Van Geel WJ, De Reus HP, Vos PE, Verbeek MM. Serumand CSF-concentrations of brain specific proteins in hydrocephalus. Acta Neurochir (Wien) 2003; 145: 37-43.
3. Burbach GJ, Hellweg R, Haas CA, et al. Induction of brain-derived neurotrophic factor in plaque-associated glial cells of aged APP23 transgenic mice. J Neurosci 2004; 24: 2421-30

4. Cassiani-Ingoni R, Muraro PA, Magnus T, et al., Disease progression after bone marrow transplantation in a model of multiple sclerosis is associated with chronic microglial and glial progenitor response. J Neuropathol Exp Neurol 2007; 66: 637-49.

5. Conner JM, Lauterborn JC, Yan Q, Gall CM, Varon S. Distribution of brainderived neurotrophic factor (BDNF) protein and mRNA in the normal adult rat CNS: evidence for anterograde axonal transport. J Neurosci 1997; 17: 2295-313.

6. Diemel LT, Jackson SJ, Cuzner ML. Role for TGF-beta1, FGF-2 and PDGF-AA in a myelination of CNS aggregate cultures enriched with macrophages. J Neurosci Res 2003; 74: 858-67.

7. Ebers GC. The natural history of multiple sclerosis. Neurol Sci 2000; 21(4 Suppl 2): S815-7.

8. Frota ER, Rodrigues DH, Donadi EA, Brum DG, Maciel DR, Teixeira AL. Increased plasma levels of brain derived neurotrophic factor (BDNF) after multiple sclerosis relapse. Neurosci Lett 2009; 460: 130-2.

9. Hammarberg H, Piehl F, Risling M, Cullheim S. Differential regulation of trophic factor receptor mRNAs in spinal motoneurons after sciatic nerve transection and ventral root avulsion in the rat. J Comp Neurol 2000; 426: 587-601.

10. Hemmer B, Archelos JJ, Hartung HP. New concepts in the immunopathogenesis of multiple sclerosis. Nat Rev Neurosci 2002; 3: 291-301.

11. Hofer MM, Barde YA. Brain-derived neurotrophic factor prevents neuronal death in vivo. Nature 1988; 331: 261-2.

12. Hohlfeld R, Kerschensteiner M, Stadelmann C, Lassmann H, Wekerle H. The neuroprotective effect of inflammation: implications for the therapy of multiple sclerosis. J Neuroimmunol 2000; 107: 161-6.

13. Kerschensteiner M, Gallmeier E, Behrens L, et al., Activated human T cells, B cells, and monocytes produce brain-derived neurotrophic factor in vitro and in inflammatory brain lesions: a neuroprotective role of inflammation? J Exp Med 1999; 189: 865-70

14. Knott C, Stern G, Kingsbury A, Welcher AA, Wilkin GP. Elevated glial brainderived neurotrophic factor in Parkinson's diseased nigra. Parkinsonism Relat Disord. 2002; 8: 329-41.

15. Korhonen L, Riikonen R, Nawa H, Lindholm D. Brain derived neurotrophic factor is increased in cerebrospinal fluid of children suffering from asphyxia. Neurosci Lett 1998; 240: 151-4.

16. Lu B, Gottschalk W. Modulation of hippocampal synaptic transmission and plasticity by neurotrophins. Prog Brain Res 2000; 128: 231-41.

17. McTigue DM, Horner PJ, Stokes BT, Gage FH. Neurotrophin-3 and brain-derived neurotrophic factor induce oligodendrocyte proliferation and myelination of regenerating axons in the contused adult rat spinal cord. J Neurosci 1998; 18: 5354-65.

18. Murase K, Nabeshima T, Robitaille Y, Quirion R, Ogawa M, Hayashi K. NGF level of is not decreased in the serum, brain-spinal fluid, hippocampus, or parietal cortex of individuals with Alzheimer's disease. Biochem Biophys Res Commun 1993; 193: 198-203.

19. Noseworthy JH, Lucchinetti C, Rodriguez M, Weinshenker BG. Multiple sclerosis. N Engl J Med 2000; 343: 938-52.

20. Parain K, Murer MG, Yan Q, et al., Reduced expression of brain-derived neurotrophic factor protein in Parkinson's disease substantia nigra. Neuroreport 1999; 10: 557-61.

21. Poo MM. Neurotrophins as synaptic modulators. Nat Rev Neurosci. 2001; 2: 24-32.

22. Prineas JW, Barnard RO, Kwon EE, Sharer LR, Cho ES. Multiple sclerosis: remyelination of nascent lesions. Ann Neurol 1993; 33: 137-51.

23. Salehi Z, Mashayekhi F. Brain-derived neurotrophic factor concentrations in the cerebrospinal fluid of patients with Parkinson's disease. J Clin Neurosci 2009; 16: $90-3$.

24. Sawada H, Ibi M, Kihara T, Urushitani M, Nakanishi M, Akaike A, Shimohama $\mathrm{S}$. Neuroprotective mechanism of glial cell line-derived neurotrophic factor in mesencephalic neurons. J Neurochem 2000; 74: 1175-84.

25. Stadelmann C, Kerschensteiner M, Misgeld T, Brück W, Hohlfeld R, Lassmann $\mathrm{H}$. BDNF and gp145trkB in multiple sclerosis brain lesions: neuroprotective interactions between immune and neuronal cells? Brain 2002; 125: 75-85.

26. Swingler RJ, Compston D. The distribution of multiple sclerosis in the United Kingdom. J Neurol Neurosurg Psychiatry 1986; 49: 1115-24.

27. Timmusk T, Belluardo N, Metsis M, Persson H. Widespread and developmentally regulated expression of neurotrophin- 4 mRNA in rat brain and peripheral tissues. Eur J Neurosci. 1993; 5: 605-13.

Received: $21 / 08 / 2011$

Accepted in revised form: 04/11/2011

\section{Corresponding author:}

Dr Farhad Mashayekhi, Associate Professor, Department of Cell and Molecular Biology, Islamic Azad University, Tonekabon branch, Tonekabon, Iran; e-mail: umistbiology@yahoo.co.uk 